\section{Immunophenotyping of chronic B-cell neoplasms: flow cytometry versus immunohistochemistry}

\author{
Afaf Abdel-Aziz Abdel-Ghafar, \\ Manal Ahmed Shams El Din El Telbany, \\ Hanan Mohamed Mahmoud, \\ Yasmin Nabil El-Sakhawy \\ Clinical and Chemical Pathology, Faculty \\ of Medicine, Ain Shams University, Cairo, \\ Egypt
}

\section{Abstract}

Morphological differentiation between benign and malignant lymphoproliferative disorders (LPDs) can be challenging. Immunophenotyping (IPT) by either technique, flow cytometry or immunohistochemistry (IHC), is an important step in solving such difficulty. Thirty-five newly diagnosed patients with chronic B-cell neoplasms (11 chronic lymphocytic leukemia, 22 non Hodgkin lymphoma and 2 hairy cell leukemia) were included in this study with age range from 20 to 70 years. Monoclonal antibodies surface expression using lymphoproliferative disorders panel (CD45, CD19, CD5, CD10, CD11c, CD20, CD22, CD23, CD38, CD79b, FMC7, CD103, CD25, kappa and lambda light chains) by flow cytometry was done on bone marrow samples. CD20, CD5, CD23, Bcl-2, Bcl-6, kappa and lambda light chain immunostaining were performed on fixed bone marrow trephine biopsy specimen. The sensitivity of IHC was $81.8 \%$ in chronic lymphocytic leukemia (CLL) and 100\% in non Hodgkin lymphoma (NHL) as regards CD20, 100\% in both groups as regards CD5, $46 \%$ in CLL and $66.7 \%$ in NHL as regards CD23, 33.3\% in CLL and 50\% in NHL as regards kappa chain, $20 \%$ in CLL and $33.3 \%$ in NHL as regards lambda chain. We found that IHC and flow cytometry are equally effective in diagnosing CLL; however, IHC might be slightly more sensitive than flow cytometry in detecting bone marrow infiltration in NHL and hairy cell leukemia (HCL).

\section{Introduction}

Distinguishing benign and malignant lymphoproliferative disorders (LPDs) by purely morphologic criteria can be difficult. Immunophenotypic analysis is a useful adjunct to the morphologic evaluation of LPDs and is of considerable assistance in resolving difficult diagnostic dilemmas. The advent of immunophenotyping (IPT) of samples from patients with LPDs has added much for proper diagnosis and classification and for better understanding of the pathogenetic mechanisms underlying the development of these disorders. ${ }^{1}$

There are several ways for testing cell markers, such as flow cytometry in which suspensions of viable or fixed cells are tested, and immunohistochemistry which studies cells in frozen or paraffin-embedded sections from bone marrow biopsy specimens or other hemopoietic tissues. ${ }^{2}$

In immunohistochemistry (IHC), morphology and antigen label can be visualized simultaneously by light microscopy which is not the case in flow cytometry, enabling accurate identification of the cells or region of interest. ${ }^{3}$ It is considered more suitable in the detection of partial or focal involvement by neoplastic cells and it is also more beneficial in nuclear antigen assessment. ${ }^{4}$ Another privilege of IHC is the long-term preservation of the biological specimen after processing and the ability to re-examine it at any time. ${ }^{5}$

The aim of this study was to to identify the diagnostic role of IHC in chronic B-cell neoplasms using a selected panel of monoclonal antibodies and to compare this role to that of flow cytometry.

\section{Materials and Methods}

\section{Subjects}

This study comprised 35 newly diagnosed chronic B-cell neoplasms adult patients attending the hematological unit of clinical pathology department, Ain Shams University, Cairo, Egypt. Patients were recruited to the study on the basis of clinical, laboratory, bone marrow aspirate and trephine biopsy findings and immunophenotypic criteria of chronic B-cell neoplasms. Sometimes lymph nodes biopsy results were provided to confirm the diagnosis.

They were 22 males and 13 females with a male to female ratio 1.7:1.0. Their ages ranged from 20 to 70 years old with mean of $51 \pm 15.2$ years. The 35 patients were divided into 3 groups: chronic lymphocytic leukemia (CLL) group (11 patients), non Hodgkin lymphoma (NHL) group (22 patients) and hairy cell leukemia (HCL) group (2 patients). The $22 \mathrm{NHL}$ cases comprised 8 mantle cell lymphomas, 6 follicular lymphomas, 5 diffuse large B-cell lymphomas and 3 Burkitt's lymphomas.

Patients were subjected to clinical sheet details (with special concern to organomegaly, lymphadenopathy, fever and weight loss), complete blood count with examination of peripheral blood smears stained with Leishman stain, bone marrow aspiration, bone marrow trephine biopsy, flow cytometric immunophenotyping for cases in leukemic phase using lymphoproliferative disorders panel (CD45, CD19, CD5, CD10, CD11c, CD20, CD22, CD23, CD38, CD79b, FMC7, CD103, CD25, kappa and lambda light chains). CD20, CD5, CD23, Bcl-2, Bcl-6, kappa and lambda light
Correspondence: Yasmin Nabil, Clinical and Chemical Pathology, Faculty of Medicine, Ain Shams University, El Abbassia Square, Cairo, Egypt.

Tel. +20.224.845.802 - Fax: +20.224.845.802.

E-mail: yasminnabil@hotmail.com

Key words: chronic B- LPD, immunohistochemistry, immunophenotyping.

Received for publication: 26 August 2011.

Revision received: 4 November 2011.

Accepted for publication: 22 December 2011.

This work is licensed under a Creative Commons Attribution NonCommercial 3.0 License (CC BYNC 3.0).

(C)Copyright A.A.A. Abdel-Ghafar et al., 2012

Licensee PAGEPress, Italy

Hematology Reports 2012; 4:e3

doi:10.4081/hr.2012.e3

chain immunostaining was performed on fixed bone marrow trephine biopsy specimen.

\section{Specimens}

Two milliliters peripheral blood samples were collected in a sterile ethylene-diamine-tetraacetic acid (EDTA) containing vaccutainers for CBC. Bone marrow (BM) aspiration was withdrawn; the first few drops were spread on glass slides for morphological examination and $1 \mathrm{~mL}$ into sterile EDTA containing vacutainers for IPT. For IPT by flow cytometry samples were processed within 24 hours. BM trephine core biopsy was obtained and transferred immediately in a sterile plastic cup containing aldehyde solution as a fixative.

\section{Methods}

\section{Flow cytometry}

Samples were processed using whole blood lysis method and analysis was done using 4 colour flow cytometric analyzer (Coulter EPICSXL flow cytometer with system II software) USA. FCM quality control including alignment, calibration, and color compensation was performed before sample acquisition according to manufacturer's instructional manual. Samples were diluted 1:1 with phosphate buffered-saline (PBS), $\mathrm{pH}$ 7.4 (Sigma Chemicals, St Louis). The final cell count suspension was adjusted between 5 and $10 \times 10^{9} / \mathrm{L}$ : $50 \mathrm{uL}$ of each sample was pipetted in two tubes (one test tube and one control tube); 5 uL of MoAbs fluorescin isothiocyanate (FITC), or phycoerythrin (PE) labeled (Provided by Coulter electronics, USA) were added to the test tube while $5 \mathrm{uL}$ of isotype matched conjugated Igs to determine the non specific binding were added to the control tube. Tubes were gently vortexed and incubated $15 \mathrm{~min}$ at room temperature in the dark. One mL lysing solution was added to each 
tube for 2-5 min and mixed well. At the end $1 \mathrm{~mL}$ PBS was added. Sequential gates were applied; initially, the lymphoid cells window was defined by forward scatter/side scatter and CD45/side scatter patterns. At least $20 \%$ of cells should express the marker to be considered positive for immunophenotyping panel. For all monoclonal expression both percent positivity and staining intensity of cells were determined.

\section{Immunohistochemistry}

Fixation was performed for 24 hours then decalcification of the core was done using disodium EDTA for 48 hours. This was followed by passing the core in serial concentrations of ethyl alcohol (50\%, 70\%, 85\%, 90\%, and 100\%) ending with xylene then wax followed by paraffin embedding. Serial 3- $\mu$ m sections were cut from the paraffin block, mounted on positively charged slides and dried overnight in a $60^{\circ} \mathrm{C}$ oven. Deparaffinization in xylene for 24 hours followed by hydration in descending grades of alcohol; $100 \%$, $90 \%, 85 \%$ and $70 \%$ was done. Antigen unmasking was done by heat induced epitope retrieval (HIER) method using antigen retrieval solution (Dako, Denmark) with PH 6.0, for a period of 20 min in a microwave at 800 Watt.

Endogenous peroxidase activity was blocked by incubation of the tissue section with $3 \%$ hydrogen peroxide in water for $30 \mathrm{~min}$ followed by incubation with the primary monoclonal antibody (Dako, Denmark) (Table 1). The streptavidin-biotin method with the horseradish peroxidase enzyme was used as a detection kit (LSAB2, Dako, Denmark). The sections were then counterstained in Meyer hematoxylin, cover-slipped by DPX mount media and examined under light microscope. The positivity of the immunostaining was detected by percentage of positive cells, intensity and pattern of staining (Table 1). According to percentage of positive cells: four grades were identified; 0 : no reaction, $1+:<5 \%$, $2+: \quad 5-9 \%, 3+: \quad 10-20 \%$ and $4+: \geq 20 \%$. Monoclonality was confirmed by either $\kappa / \lambda$ ratios of more than 3 ( $\kappa$ clone) or less than $0.4(\lambda$ clone). ${ }^{4}$

\section{Statictical analysis}

Data was analyzed statistically using statistical package for social science (SPSS version 15.0.1). The following tests were done: descriptive statistics including quantitative data (mean \pm standard deviation) for parametric results and in the form of median and range in non parametric ones) and qualitative data (number and percentage), analytical statistics including $\chi^{2}$, Fisher's exact test, Wilcoxon Rank-sum test (Z-value) and regarding quantitative parametric data using Student test ( $\mathrm{t}$-value).

\section{Results}

In the CLL group (11 patients), the BM aspirate lymphocytes percentage ranged from $40 \%$ to $98 \%$ with a mean of $82.9 \% \pm 16.0$. In the NHL cases (22 patients), the BM aspirate lymphocytes ranged from $6 \%$ to $92 \%$ with a mean of $24.8 \% \pm 22.9$. Seven $(31.8 \%)$ cases of the NHL group had BM lymphocyte count $\geq 30 \%$ (BM infiltration), while 13 (59.1\%) cases had lymphocyte count $<30 \%$. Dry tap was observed in 2 cases. Bone marrow trephine biopsy showed lymphocytic infiltration in all patients. In the CLL group, ten cases showed diffuse pattern of infiltration with packed marrow and one case showed interstitial pattern of infiltration together with scattered nodules of small lymphocytes. In the NHL group, the predominant pattern of infiltration was the mixed pattern $(8 / 22,36.4 \%)$, followed by the focal pattern $(7 / 22,31.8 \%)$, the interstitial pattern $(4 / 22,18.2 \%)$ and the diffuse pattern $(3 / 22$, $13.6 \%)$. In the two HCL cases, both showed mixed (patchy and interstitial) pattern of infiltration.

\section{Flow cytometry}

All CLL cases had a score of 4-5 while in the NHL group the score was 0-2 according to Matutes and Moreau, ${ }^{6,7}$ immunophenotyping on BM aspirate was performed in infiltrated cases which were 7 out of 22 cases (Figures 1,2).

Table 1. Monoclonal antibodies.

\begin{tabular}{lccccc}
$\begin{array}{l}\text { Primary } \\
\text { antibody }\end{array}$ & Clone & Dilution & $\begin{array}{c}\text { Time of } \\
\text { inculbation }\end{array}$ & Grade & Pattern of staining \\
CD20 & L26 & Ready to use & One hour & $4+$ & Membranous/Cytoplasmic \\
CD5 & CD5/54/F6 & Ready to use & One hour & $3+$ & Membranous/Cytoplasmic \\
\hline CD23 & MHM6 & $1: 5$ & One hour & $3+$ & Membranous/Cytoplasmic \\
Bcl-2 & 124 & Ready to use & One hour & $4+$ & Membranous/Cytoplasmic \\
\hline Bcl-6 & PG-B6p & $1: 10$ & Overnight at $4^{\circ} \mathrm{C}$ & $3+$ & Nuclear \\
Kappa & R10-21-F3 & Ready to use & Two hours & $2+$ & Perinuclear/Granular cytoplasmic \\
\hline Lambda & N10/2 & Ready to use & Two hours & $2+$ & Perinuclear/Granular cytoplasmic \\
\hline
\end{tabular}

All monoclonals were purchased from life trade company Egypt imported from Dako Denmark.

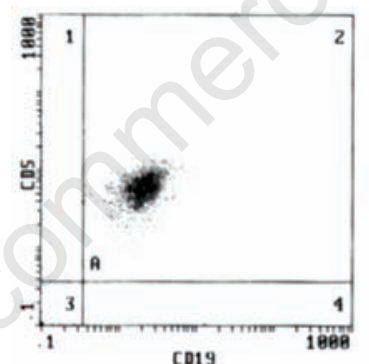

CD19
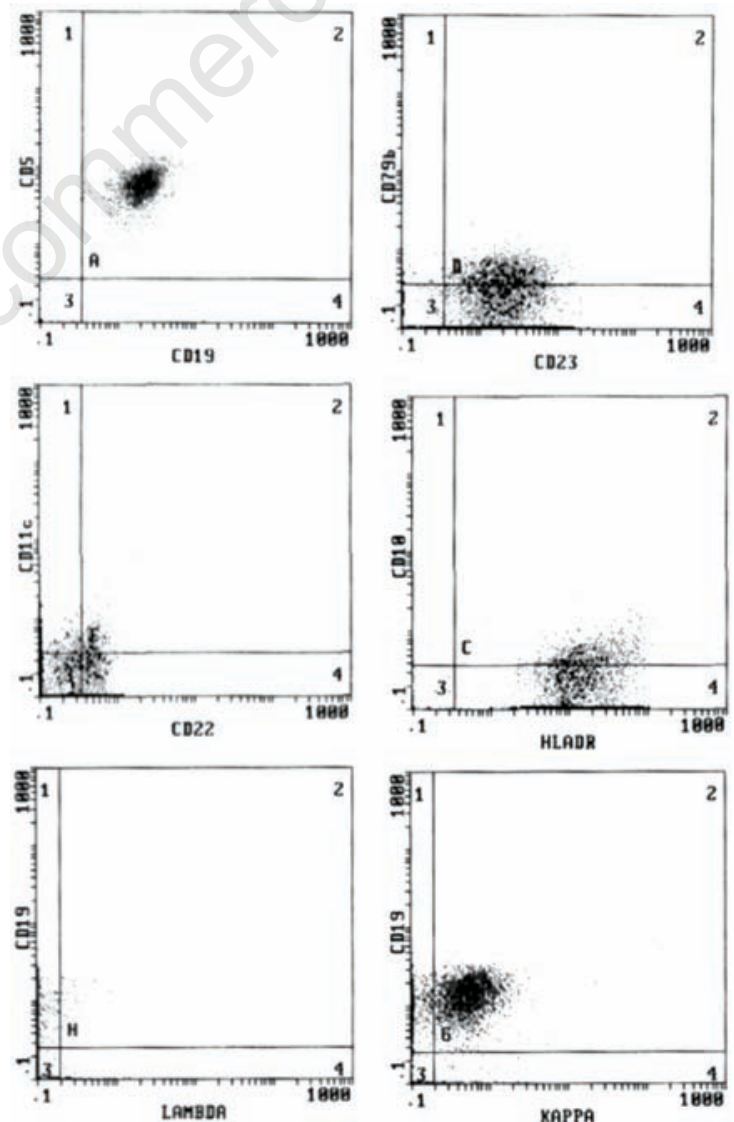
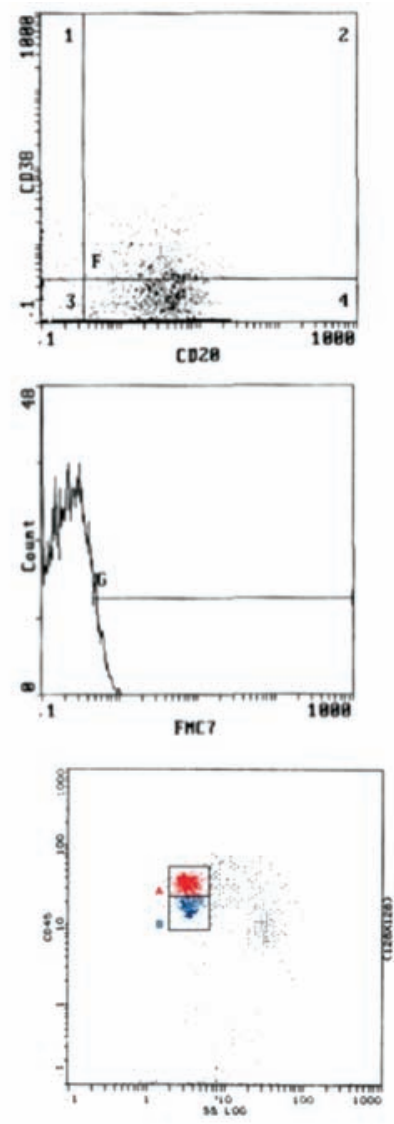

Figure 1. Flow cytometric analysis of a case of chronic lymphocytic leukemia (score=5). 
In CLL group, all cases (100\%) revealed CD19, CD20 (72.7\% of them with dim intensity), CD5 and CD23, 87.5\% expressed CD22, $67.5 \%$ were negative for CD79b, $77.5 \%$ were negative for FMC7 and 35\% expressed CD38. SmIg light chain restriction showed $\kappa$ restriction in $54.5 \%$ and $\lambda$ in $45.5 \%$ of cases. In NHL group, the lymphocytes expressed pan B cell markers, CD19 (100\%), CD20 (100\% with bright intensity), CD22 (85.7\%) and CD79b (85.7\%, bright expression); CD5 and CD23 were expressed in $3 / 7$ cases (42.9\%); CD10 was expressed in one case.

\section{Immunohistochemistry}

Figures 3-8 show examples of immunohistochemistry results. CD20 showed positivity in $81.8 \%$ (9/11) of the CLL group showing $45.4 \%$ of cases with strong intensity, $18.2 \%$ with moderate intensity and $18.2 \%$ with weak intensity. In NHL group, positivity was detected in $95.5 \%$ (21/22) of cases showing $45.5 \%$ of cases with strong intensity, $36.4 \%$ with moderate intensity and $13.6 \%$ showed weak intensity in NHL group. Concerning CD5, it was expressed in 100\% (11/11) with $45.5 \%$ showed strong intensity, $36.3 \%$ with moderate intensity and $18.2 \%$ with weak intensity in CLL group, 50\% (11/22) of cases showing $22.8 \%$ with strong intensity, $18.2 \%$ with moderate intensity and $9 \%$ with weak intensity in the NHL.

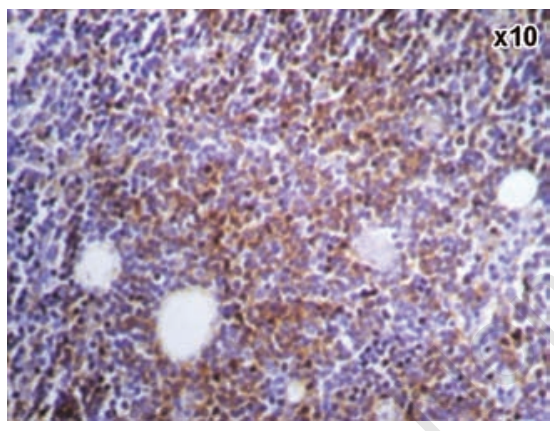

Figure 3. A case of chronic lymphocytic leukemia showing positive CD20.

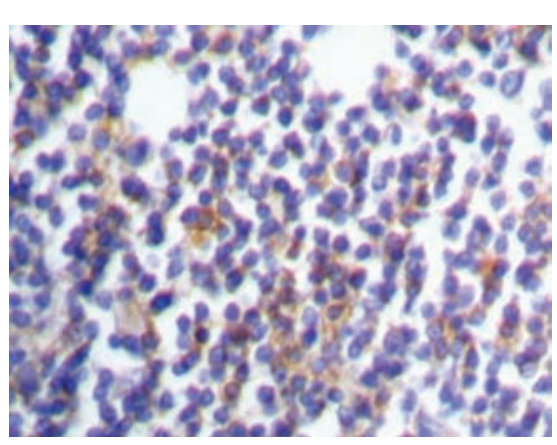

Figure 6. Light chain restriction: kappa restriction in a case of chronic lymphocytic leukemia.
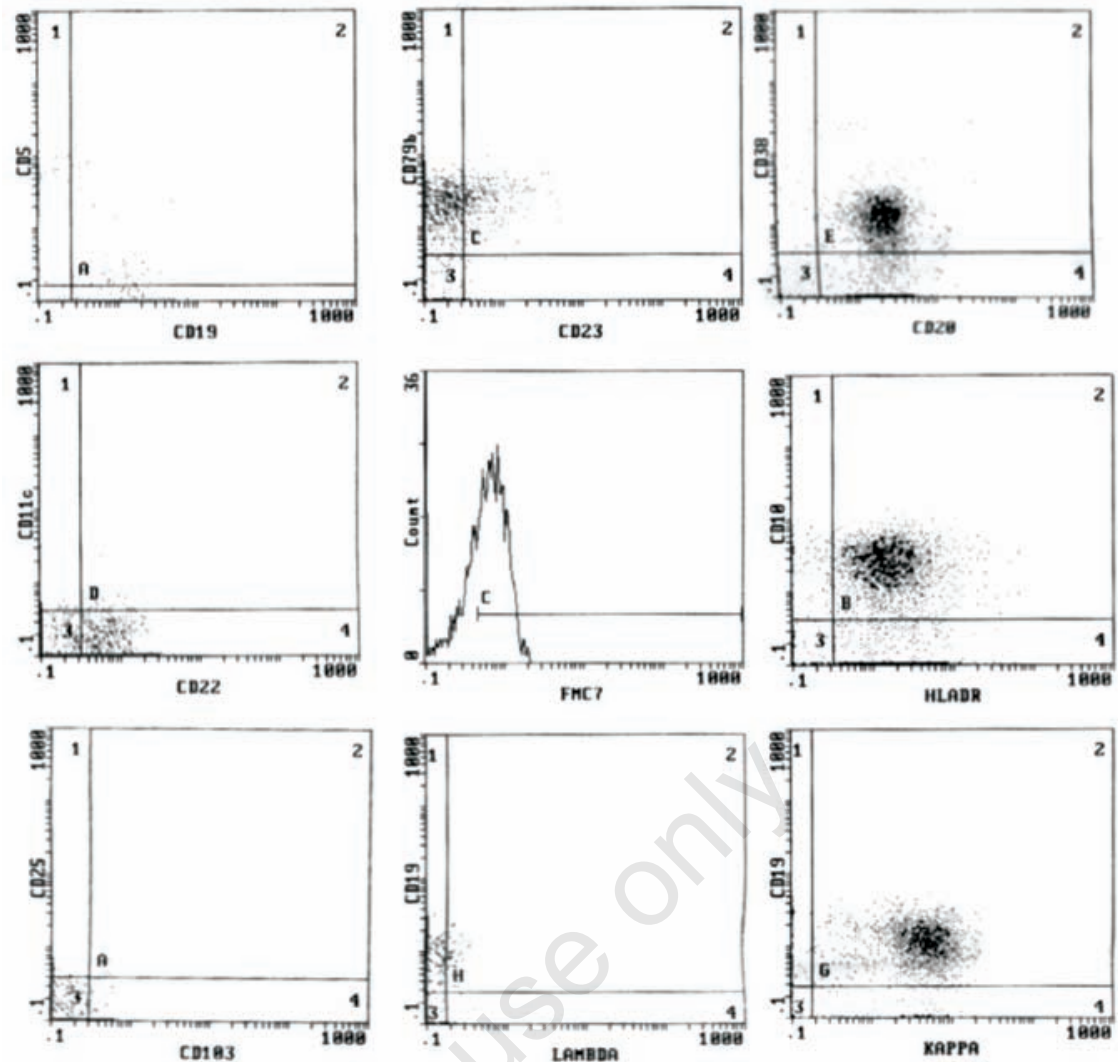

Figure 2. Flow cytometric analysis of a case of non Hodgkin lymphoma (score=2).

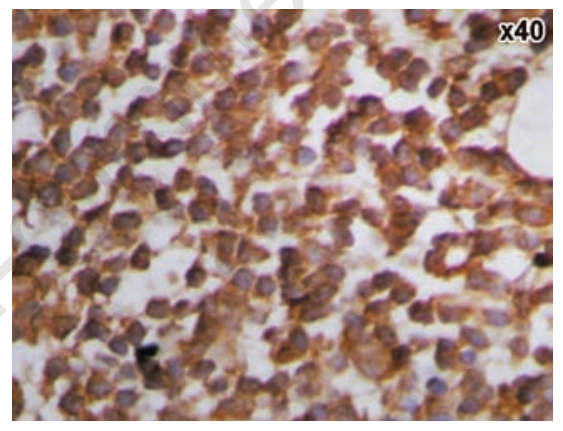

Figure 4. A case of chronic lymphocytic leukemia showing positive CD5.

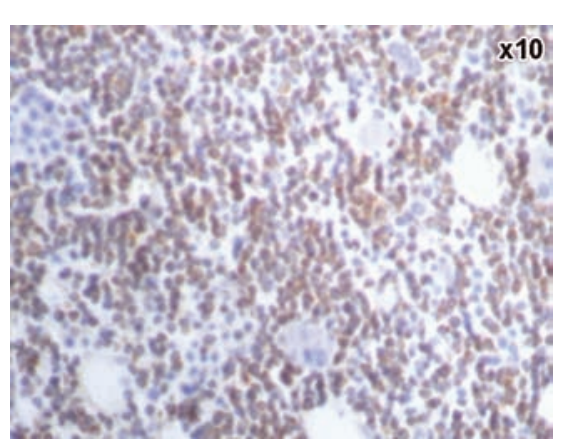

Figure 7. A case of chronic lymphocytic leukemia showing positive $\mathrm{Bcl} 2$.

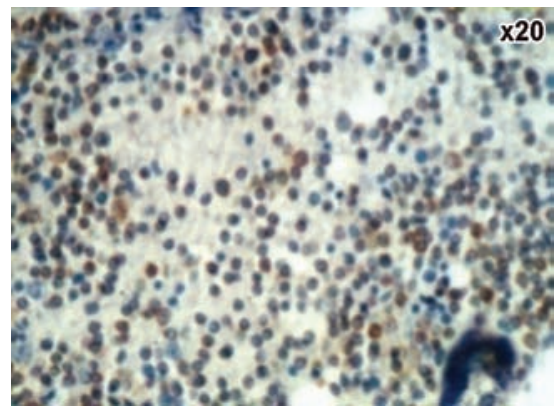

Figure 5. A case of chronic lymphocytic leukemia showing positive CD23.

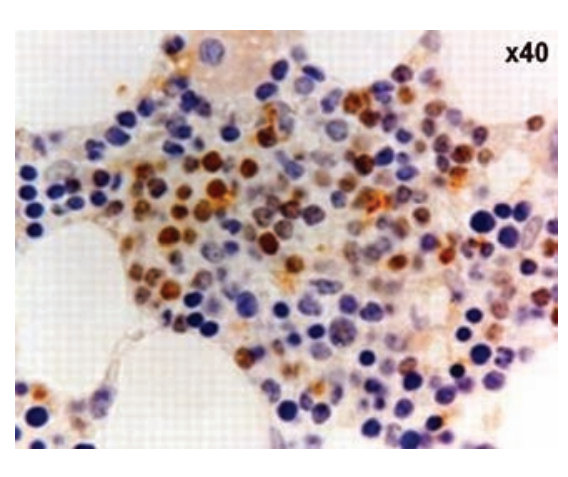

Figure 8. A case of Diffuse large B-cell lymphoma showing positive Bcl6. 
As regards CD23, it was expressed in 45.5\% (5/11) showing 9\% with strong intensity, 9\% with moderate intensity and $27.5 \%$ with weak intensity and in $13.6 \%(3 / 22)$ of cases of the CLL group. All cases of NHL showed weak intensity. Three cases (27.7\%) of the CLL group, all of them had weak intensity and 12/22 (54.5\%) of NHL group showed light chain restriction with all cases had moderate intensity. As for Bcl-2 protein, it was positive in $54.5 \%(6 / 11)$ \& in $36.4 \%(8 / 22)$ of cases of the CLL and NHL groups. Bcl-6 was positive in $13.6 \%(3 / 22)$ of NHL cases and it was negative in CLL group.

\section{Comparing immunohistochemistry to flow cytometry results}

The percent positivity of markers and staining intensity done using IHC were compared to the percent positivity and to the mean fluorescence intensity of these markers using flow cytometry. In the CLL group, no statistical significance was found regarding all markers except for CD20 mean fluorescence intensity $(\mathrm{P}=0.002)$, however, within the NHL group, there was a significant relation between the percent positivity of both flow cytometry and IHC regarding $\mathrm{CD} 20$ ( $\mathrm{P}=0.01)$, CD5 ( $\mathrm{P}=0.02)$, $\mathrm{CD} 23(\mathrm{P}=0.049), \kappa(\mathrm{P}=0.025)$ and highly significant one for $\lambda(P=0.006)$ (Table 2$)$. The significant association was restricted to CD20 and CD5 when comparing their IHC positivity to MFI by flow cytometry $(\mathrm{P}=0.002$ and 0.04 respectively) (Table 3). On the other hand, comparing the IHC staining intensity (graded as strong, moderate and weak) to the flow cytometry results showed a high statistical significance as regards CD5 either its percent positivity or its MFI ( $\mathrm{P}=0.008,0.039$ respectively). Another significance was found regarding CD20 MFI $(\mathrm{P}=0.049)$. No statistical significance was found as regards other markers.

\section{Sensitivity of immunohistochemistry markers}

The sensitivity of IHC markers was calculated in both CLL and NHL groups which revealed a sensitivity of $81.8 \%$ for the CLL group and $100 \%$ in NHL group as regards CD20, 100\% in both groups as regards CD5, 46\% in CLL group and $66.7 \%$ in NHL group as regards CD23, 33.3\% in CLL group and 50\% in NHL group as regards kappa, 20\% in CLL group and 33.3\% in NHL group as regards lambda (Table 4).

\section{Discussion}

Modern hematopathology relies heavily on immunophenotyping both for distinguishing benign from malignant processes as well as for accurate subclassification. In addition, paraf- fin section immunophenotyping allows us to make diagnoses on small biopsies that would have previously been considered suspicious for infiltration. In addition to the numerous commercially available antibodies, advances in heat-induced epitope retrieval allow one to obtain a detailed immunophenotype in routinely processed lymphomas that was only possible using flow cytometry or frozen section immunostaining. ${ }^{8}$

Although the use of antibody panels is standard in flow cytometry, the study of a full panel of paraffin-reactive antibodies in the workup of B-cell lymphoid neoplasms is not so prevalent. A full immunophenotype and determination of monoclonality (immunoglobulin (Ig) light chain restriction) may be difficult using IHC because of the destruction of some of the antigenic epitopes by the fixation and decalcification process used for BMB specimens. ${ }^{9}$ In addition, some markers that are useful by flow cytometry are simply not routinely available for paraffin IHC. 10

The aim of this study was to identify the diagnostic role of IHC in chronic B-cell neoplasms using a selected panel of monoclonal

Table 2. Comparing percent positivity of immunohistochemistry and flow cytometry in chronic lymphocytic leukemia and non Hodgkin lymphoma groups.

\begin{tabular}{|c|c|c|c|c|c|}
\hline \multicolumn{2}{|c|}{ Marker } & $\begin{array}{c}\text { IHC (No of } \\
\text { positive cases) }\end{array}$ & $\begin{array}{l}\text { Flow cytometry } \\
\text { (\% positivity) }\end{array}$ & $\mathbf{P}$ & Sig \\
\hline CD20 & $\begin{array}{l}\text { CLL } \\
\text { NHL }\end{array}$ & $\begin{array}{c}9 \\
21\end{array}$ & $\begin{array}{l}76.9 \\
49.1\end{array}$ & $\begin{array}{c}0.814 \\
0.01\end{array}$ & $\begin{array}{c}\mathrm{NS} \\
\mathrm{S}\end{array}$ \\
\hline CD5 & $\begin{array}{l}\text { CLL } \\
\text { NHL }\end{array}$ & $\begin{array}{l}11 \\
11\end{array}$ & $\begin{array}{c}53.1 \\
6.3\end{array}$ & $\begin{array}{c}0.237 \\
0.02\end{array}$ & $\begin{array}{c}\text { NS } \\
\text { S }\end{array}$ \\
\hline CD23 & $\begin{array}{l}\text { CLL } \\
\text { NHL }\end{array}$ & $\begin{array}{l}5 \\
3\end{array}$ & $\begin{array}{c}67.2 \\
6.1\end{array}$ & $\begin{array}{l}0.118 \\
0.049\end{array}$ & $\begin{array}{c}\text { NS } \\
\text { S }\end{array}$ \\
\hline Карра & $\begin{array}{l}\text { CLL } \\
\text { NHL }\end{array}$ & $\begin{array}{l}2 \\
5\end{array}$ & $\begin{array}{c}35 \\
16.8\end{array}$ & $\begin{array}{l}0.231 \\
0.025\end{array}$ & $\begin{array}{c}\text { NS } \\
\text { S }\end{array}$ \\
\hline Lambda & $\begin{array}{l}\text { CLL } \\
\text { NHL }\end{array}$ & $\begin{array}{l}1 \\
7\end{array}$ & $\begin{array}{l}2.4 \\
5.9\end{array}$ & $\begin{array}{l}0.251 \\
0.006\end{array}$ & $\begin{array}{l}\text { NS } \\
\text { HS }\end{array}$ \\
\hline
\end{tabular}

ICH, immunohistochemistry; CCL, chronic lymphocytic leukemia; NHL, non Hodgkin lymphoma; NS, Non-significant; S, Significant; HS, Highlysignificant.

Table 3. Comparing percent positivity of immunohistochemistry and flow cytometry mean fluorescence intensity in chronic lymphocytic leukemia and non Hodgkin lymphoma groups.

\begin{tabular}{|c|c|c|c|c|c|}
\hline$N$ & & $\begin{array}{c}\text { IHC (No of } \\
\text { positive cases) }\end{array}$ & $\begin{array}{l}\text { Flow cytometry } \\
\text { (MFI) }\end{array}$ & $\mathbf{P}$ & Sig. \\
\hline CD20 & $\begin{array}{l}\text { CLL } \\
\text { NHL }\end{array}$ & $\begin{array}{c}9 \\
21\end{array}$ & $\begin{array}{c}1.77 \\
20\end{array}$ & $\begin{array}{l}0.002 \\
0.002\end{array}$ & $\begin{array}{l}\text { HS } \\
\text { HS }\end{array}$ \\
\hline CD5 & $\begin{array}{l}\text { CLL } \\
\text { NHL }\end{array}$ & $\begin{array}{l}11 \\
11\end{array}$ & $\begin{array}{c}2.69 \\
0\end{array}$ & $\begin{array}{l}0.97 \\
0.04\end{array}$ & $\begin{array}{c}\text { NS } \\
\text { S }\end{array}$ \\
\hline CD23 & $\begin{array}{l}\text { CLL } \\
\text { NHL }\end{array}$ & $\begin{array}{l}5 \\
3\end{array}$ & $\begin{array}{c}1.56 \\
0\end{array}$ & $\begin{array}{c}0.3 \\
0.19\end{array}$ & $\begin{array}{l}\text { NS } \\
\text { NS }\end{array}$ \\
\hline Карра & $\begin{array}{l}\text { CLL } \\
\text { NHL }\end{array}$ & $\begin{array}{l}2 \\
5\end{array}$ & $\begin{array}{c}1.1 \\
1.58\end{array}$ & $\begin{array}{l}0.3 \\
0.5\end{array}$ & $\begin{array}{l}\text { NS } \\
\text { NS }\end{array}$ \\
\hline Lambda & $\begin{array}{l}\text { CLL } \\
\text { NHL }\end{array}$ & $\begin{array}{l}1 \\
7\end{array}$ & $\begin{array}{l}0 \\
0\end{array}$ & $\begin{array}{l}0.22 \\
0.45\end{array}$ & $\begin{array}{l}\text { NS } \\
\text { NS }\end{array}$ \\
\hline
\end{tabular}

ICH, immunohistochemistry; CCL, chronic lymphocytic leukemia; NHL, non Hodgkin lymphoma; NS, Non-significant; S, Significant; HS, Highlysignificant.

Table 4. Sensitivity of immunohistochemistry markers in chronic lymphocytic leukemia and non Hodgkin lymphoma groups.

\begin{tabular}{lccc} 
& CLL & NHL & Total \\
CD20 & $81.8 \%$ & $100 \%$ & $90 \%$ \\
CD5 & $100 \%$ & $100 \%$ & $100 \%$ \\
\hline CD23 & $46 \%$ & $66.7 \%$ & $50 \%$ \\
Kappa & $33.3 \%$ & $50 \%$ & $40 \%$ \\
\hline Lambda & $20 \%$ & $33.3 \%$ & $25 \%$ \\
\hline
\end{tabular}

CCL, chronic lymphocytic leukemia; NHL, non Hodgkin lymphoma. 
antibodies and to compare this role to that of flow cytometry. Thirty five newly diagnosed patients having chronic B-LPDs were studied in the current study; they were classified into three groups (CLL, NHL and HCL).

Flow cytometry on bone marrow aspirate samples of CLL and infiltrated cases of NHL and IHC were performed on BMB samples using a panel of markers: CD20, CD5, CD23, Bcl2, Bcl6, kappa and lambda light chain.

Comparing IHC results with flow cytometry, the current study detected IHC sensitivity $90 \%$, $100 \%, 50 \%, 40 \%$ and $25 \%$ for CD20, CD5, CD23, kappa and lambda respectively. The sensitivity of light chain by IHC was $33.3 \%$ in CLL and $50 \%$ in NHL as regards kappa chain, $20 \%$ in CLL and $33.3 \%$ in NHL as regards lambda chain.

Biesemier and his colleagues ${ }^{11}$ compared IHC fresh frozen tissues to flow cytometry. They obtained lower concordant results as regards CD20 and CD5 being 86\% and 80\% respectively. The sensitivity of light chain restriction by IHC was $30 \%$ which is near to that in the present study.

In a study by El-Sayed and colleagues in $2008^{1}$ done on Egyptians, they measured the overall concordance between IHC and flow cytometry without specifying each marker. The results of the study showed $88 \%$ concordance between flow cytometry and histopathology/ IHC in the diagnosis of lymphoma. Similar results were obtained by Mandacova et al. ${ }^{12}$ and Martinez et al. ${ }^{13}$ who found a concordance between flow cytometry and histopathology/ IHC in $89 \%$ and $87.2 \%$ of B-lymphoma cases respectively.

In another study done on Egyptians by Asaad et al. in 2005, ${ }^{14}$ they studied CD23 and cyclin D1 immunostaining of lymph node biopsies in B-SLL/CLL and MCL cases. They found that CD23 was positive in $64 \%$ of B-CLL/SLL cases and $4 \%$ of MCL cases stained with a membranous pattern of staining.

In accordance, Sah and co-workers ${ }^{9}$ compared the results of flow cytometry, BMB and aspirates in 110 patients with B-cell lymphomas. In the CLL cases they showed a good correlation between the three parameters in over two thirds of samples and up to $88 \%$ when only flow cytometry and IHC were compared. There were very few discrepancies between flow cytometry and BMB and these were found mainly in cases with minimal residual disease (MRD). It seems, according to their study, that $\mathrm{BMB} / \mathrm{IHC}$ and flow cytometry are the best methods to assess MRD in CLL.

Previous studies investigating the role of flow cytometry in detecting BM involvement by NHL has not provided evidence of much benefit beyond morphological examination alone in the biopsy. Fineberg et al. ${ }^{15}$ and Dunphy ${ }^{16}$ found a good correlation ( $85 \%$ and $81 \%$ respectively) between morphology on BMB and flow cytometry, which can be explained in part by the inclusion of a large number of CLL cases.

A lower percentage of concordance between flow cytometry and BMB was estimated by Naughton et al. ${ }^{17}$ who reviewed 273 bone marrows from patients known to have NHL, where flow cytometry detected only $60 \%$ of positive BMB cases.

In our study, using a cut off $\geq 20 \%$, bcl- 2 protein was positive in $54.5 \%$ of CLL cases, $36.4 \%$ of NHL cases $80 \%$ of FL, $29 \%$ of MCL and $33 \%$ of Diffuse large B-cell lymphoma cases). Indeed, immunohistochemical studies have shown that, beside FL, a broad spectrum of lymphoid malignancies including CLL, plasma cell dyscrasia and Diffuse large B-cell lymphoma (DLBCL) also express the bcl-2 protein. ${ }^{18}$

Studying bcl-2 in lymphoma cases, Papakonstantinous et al. proved that the expression of bcl-2 protein is not restricted to B-cell lymphomas bearing the $\mathrm{t}(14 ; 18)$ translocation and they showed the complete absence of any correlation between bcl-2 gene rearrangements and bcl-2 expression in NHL. ${ }^{19}$

Despite using the same clone and the same cut off (20\%) as in the current study, Chang et $a l .{ }^{20}$ found $100 \%$ positivity in CLL/SLL cases (29 cases). Also Papakonstantinous et al. ${ }^{19}$ detected $92 \%$ positivity in CLL cases.

Studying only Egyptian patients with de novo nodal DLBCL, Abd El-Hameed ${ }^{21}$ found that positivity for bcl-2 (using a lower cut off level $>10 \%$ ) was detected in $60 \%$ cases.

In accordance to our results, Kondo et al. ${ }^{22}$ detected bcl- 2 protein by IHC in $75 \%$ in FL and $44 \%$ in DLBCL. Similarly, Hadzi-Pecova et al. ${ }^{23}$ found bcl- 2 protein expression in $87 \%$ of the patients with FL and in $38 \%$ of cases with DLBCL.

Using a lower cut off $>5 \%$, Llanos et al. ${ }^{24}$ found $95 \%$ of FL and $61 \%$ of DLBCL cases expressing bcl-2 protein revealing a higher percent than that in this study. Also in a recent study by Chang et al. ${ }^{20}$ they found over $75 \%$ of bcl-2 protein positivity in NHL cases with a cut off $20 \%$. Within their patients, the bcl- 2 percent positivity was $93 \%, 56 \%$ and $100 \%$ among FL (59 cases), DLBCL (77 cases) and MCL (4 cases) respectively.

As for bcl-6, the current study showed positivity in $13.6 \%(3 / 22)$ of NHL cases and it was negative in all other groups. Two out of three cases were DLBCL and one was MCL.

Despite the small sample size of DLBCL in the current study, the percent of positive cases was in agreement with Lossos et al. ${ }^{25}$ who showed expression in $63 \%$ of DLBCL cases. A slightly higher percent was obtained by Winter $^{26}$ (77\%) and Colomo ${ }^{27}$ (72\%).

A lower percent in DLBCL was obtained by Chang $^{28}$ (51\%) and Hans ${ }^{29}$ (56\%). According to
Winter et al.,${ }^{26}$ such differences may represent the underlying patient population as well as technical factors related to staining, interpretation, and scoring of positive results.

Authors were contradicting in establishing a cut off value ranging from $10-30 \% .25,27,30-33$ These differences may partly be explained by the differences in the staining techniques, for instance a study using the EnVision method and a low cut off of $10 \%$, as much as $97 \%$ of cases were found positive for bcl- $6 .^{34}$

The aberrant expression of bcl- 6 in MCL found in the current study was also experienced by some authors. Only one of 20 MCL cases studied by Chuang et al. ${ }^{35}$ expressed bcl6. Similarly, Gualco et al. ${ }^{36}$ found bcl-6 expression in $12 \%$ of the MCL cases.

We concluded that IHC can be a reliable alternative choice for IPT especially in NHL cases. Both IHC and flow cytometry are effective in diagnosing CLL; however, IHC might be slightly more sensitive than flow cytometry in detecting BM infiltration in NHL and HCL.

\section{References}

1. El-Sayed AM, El-Borai MH, Bahnassy AA, El-Gerzawi SM. Flow cytometric immunophenotyping (FCI) of lymphoma: correlation with histopathology and immunohistochemistry. Diagn Pathol 2008;3:43.

2. Matutes E, Morilla R, Catovsky D. Immunophenptyping. Dacie and Lewis Practical Haematology (Tenth Edition); 2006. pp 335-355

3. Gudgin EJ, Erber WN. Immuno-phenotyping of lymphoproliferative disorders: state of the art. Pathology 2005;37:457-78.

4. Ioachim HL, Medeiros LJ. Flow cytometry and Immunohistochemistry. In: Ioachim's lymph node pathology. Philadelphia: Lippincott Williams and Wilkins 4th edition; 2008. pp 38-57.

5. Dunphy CH. Applications of flow cytometry and immunohistochemistry to diagnostic hematopathology. Arch Pathol Lab Med 2004;128:1004-22.

6. Matutes E, Owusu-Ankomah K, Morilla R, et al. The immunological profile of B-cell disorders and proposal of a scoring system for the diagnosis of CLL. Leukemia 1994;10:1640-5.

7. Moreau EJ, Matutes E, A'Hern RP, et al. Improvement of the chronic lymphocytic leukemia scoring system with the monoclonal antibody SN8 (CD79b). Am J Clin Pathol 1997;108:378-82.

8. Hsi ED, Yegappan S. Lymphoma immunophenotyping: a new era in paraffin-section immunohistochemistry. Adv Anat Pathol 2001;8:218-39.

9. Sah SP, Matutes E, Wotherspoon AC, et al. 
A comparison of flow cytometry, bone marrow biopsy, and bone marrow aspirates in the detection of lymphoid infiltration in B cell disorders. J Clin Pathol 2003;56:12932 .

10. Higgins RA, Blankenship JE, Kinney MC. Application of immunohistochemistry in the diagnosis of non-Hodgkin and Hodgkin lymphoma. Arch Pathol Lab Med 2008;132: 441-61.

11. Biesemier KW, Dent GA, Pryzwansky KB, Folds JD. A comparative study of frozensection immunoperoxidase and flow cytometry for immunophenotypic analysis of lymph node biopsies. Clin Diagn Lab Immunol 1994;1:299-303.

12. Mandakova P, Campr V, Kodet R. Correlation of results of flow cytometry and morphologic findings in the diagnosis of malignant B-cell lymphoma. Cas Lek Cesk 2003;142:651-5.

13. Martinez A, Aymerich M, Castillo M, et al. Routine use of immunophenotype by flow cytometry in tissues with suspected hematological malignancies. Cytometry B Clin Cytom 2003;56:8-15.

14. Asaad NY, Abd El-Wahed MM, Dawoud MM. Diagnosis and Prognosis of B-Cell Chronic Lymphocytic Leukemia/Small Lymphocytic Lymphoma (B-CLL/SLL) and Mantle Cell Lymphoma (MCL). J Egypt Nat Cancer Inst 2055;17:279-90.

15. Fineberg S, Marsh E, Alfonso F, et al. Immunophenotypic evaluation of bone marrow in non-Hodgkin's lymphoma. Hum Pathol 1993;24:636-42.

16. Dunphy $\mathrm{CH}$. Combining morphology and flow cytometric immunophenotyping to evaluate bone marrow specimens for Bcells malig neoplasms. Am J Clin Pathol 1998;109:625-30.

17. Naughton MJ, Hess JL, Zutter MM, Bartlett NL. Bone marrow staging in patients with non-Hodgkin's lymphoma. Is flow cytometry a useful test? Cancer 1998;82:1154-9.

18. Pezzella F, Tse AG, Cordell JL, et al. Expression of the bcl-2 oncogene protein is not specific for the 14;18 chromosomal translocation. Am J Pathol 1990;137:22532.

19. Papakonstantinous G, Verbeke C, Hastka $\mathrm{J}$, et al. Bcl-2 expression in non-Hodgkin's lymphomas is not associated with bcl-2 gene rearrangements. $\mathrm{Br}$ Jf Haematol 2001;113:383-90.

20. Chang CM, Schroeder JC, Huang WY, et al. Non-Hodgkin lymphoma (NHL) subtypes defined by common translocations: utility of fluorescence in situ hybridization (FISH) in a case-control study. Leuk Res 2010;34:190-5.

21. Abd El-Hameed A. De novo nodal diffuse large B-cell lymphoma: identification of biologic prognostic factors. J Egypt Nat Cancer Inst 2005,1:20-8.

22. Kondo E, Yoshino T, Yamadori I, et al. Expression of BcI-2 Protein and Fas Antigen in Non-Hodgkin's Lymphomas. Am J Clin Pathol 1994;145:330-7.

23. Hadzi-Pecova L, Petrusevska G, Stojanovic A. Non-Hodgkin's lymphomas: immunologic prognostic studies. Prilozi 2007;28:3955.

24. Llanos M, Alvarez-Argüelles H, Alemán R, et al. Prognostic significance of Ki-67 nuclear proliferative antigen, bcl-2 protein, and p53 expression in follicular and diffuse large B-cell lymphoma. Med Oncol 2001;18:15-22.

25. Lossos IS, Jones CD, Warnke R, et al. Expression of a single gene, BCL-6, strongly predicts survival in patients with diffuse large B-cell lymphoma. Blood 2001;98:94551.

26. Winter JN, Weller EA, Horning SJ, et al. Prognostic significance of Bcl-6 protein expression in DLBCL treated with CHOP or R-CHOP: a prospective correlative study. Blood 2006;107:4207-13.

27. Colomo L, López-Guillermo A, Perales M, et al. Clinical impact of the differentiation profile assessed by immunophenotyping in patients with diffuse large B-cell lymphoma. Blood 2003;101:78-84.
28. Chang CC, McClintock S, Cleveland RP, et al. Immunohistochemical expression patterns of germinal center and activation Bcell markers correlate with prognosis in diffuse large B-cell lymphoma. Am J Surg Pathol 2004;28:464-70.

29. Hans CP, Weisenburger DD, Greiner TC, et al. Confirmation of the molecular classification of diffuse large B-cell lymphoma by immunohistochemistry using a tissue microarray. Blood 2004;103:275-82.

30. Barrans SL, O'Connor SJM, Evans PAS, et al. Rearrangement of the BCL6 locus at $3 q 27$ is an independent poor prognostic factor in nodal diffuse large B-cell lymphoma. Br J Haematol 2002;117:322-32.

31. Berglund M, Thunberg U, Amini RM, et al. Evaluation of immunophenotype in diffuse large B-cell lymphoma and its impact on prognosis. Mod Pathol 2005;18:1113-20.

32. Dogan A, Bagdi E, Munson P, Isaacson PG. CD10 and BCL6 expression in paraffin sections of normal lymphoid tissue and B-cell lymphomas. Am J Surg Pathol 2000;24:84652.

33. De Leval L, Harris NL. Variability in immunophenotype in diffuse large B-cell lymphoma and its clinical relevance. Histopathology 2003;43:509-28.

34. Linderoth J, Jerkeman M, Cavallin-Ståhl E, et al. Immunohistochemical expression of CD23 and CD40 may identify prognostically favorable subgroups of diffuse large Bcell lymphoma: a Nordic Lymphoma Group Study. Clin Cancer Res 2003;9:722-8.

35. Chuang SS, Huang WT, Hsieh PP, et al. Mantle cell lymphoma in Taiwan: clinicopathological and molecular study of 21 cases including one cyclin D1-negative tumor expressing cyclin D2. Pathol Int 2006;56:440-8.

36. Gualco G, Weiss LM, Harrington WJ Jr, Bacchi CE. BCL6, MUM1, and CD10 expression in mantle cell lymphoma. Appl Immunohistochem Mol Morphol 2010;18: 103-8. 